Research Paper

\title{
Identification and Knockdown of the Olfactory Receptor (OrCo) in Gypsy Moth, Lymantria dispar
}

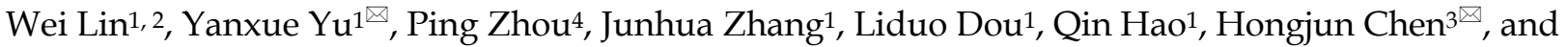
Shuifang $\mathrm{Zhu}^{1 凶}$

1. Institute of Plant Quarantine, Chinese Academy of Inspection and Quarantine, Beijing, China 100029;

2. College of Agriculture and Biotechnology, China Agricultural University, Beijing, China, 100193;

3. Division of Animal and Plant Quarantine Supervision, General Administration of Quality Supervision, Inspection and Quarantine of the People's Republic of China, Beijing, China, 100088;

4. College of Plant Protection, Shandong Agricultural University, Tai'an, Shandong Province, China, 271000

$\triangle$ Corresponding authors: Yanxue Yu, Institute of Plant Quarantine, Chinese Academy of Inspection and Quarantine, No. 11 Ronghua South Road, Yi Zhuang Economic and Technological Development Zone, Daxing District, Beijing, China 100176; Telephone: +86-010-53897559; Email: yuxue4607@aliyun.com. Hongjun Chen, Division of Animal and Plant Quarantine Supervision, General Administration of Quality Supervision, Inspection and Quarantine of the People's Republic of China, No.9 Madian Road, Haidian District, Beijing, China 100088, Telephone: +86-010-13810048962; Email: chenhj1225@263.net. Shuifang Zhu, Institute of Plant Quarantine, Chinese Academy of Inspection and Quarantine, No. 11 Ronghua South Road, Yi Zhuang Economic and Technological Development Zone, Daxing District, Beijing, China 100176; Telephone: +86-010-53897651; Email: zhusf@caiq.gov.cn.

(C) 2015 Ivyspring International Publisher. Reproduction is permitted for personal, noncommercial use, provided that the article is in whole, unmodified, and properly cited. See http://ivyspring.com/terms for terms and conditions.

Received: 2015.02.15; Accepted: 2015.04.08; Published: 2015.05.22

\begin{abstract}
The gypsy moth, Lymantria dispar, is an important economic pest that causes large-scale damage to forests worldwide. Because of its important role in initiating and controlling insect behavior, olfaction - and olfaction-based pest management - has drawn increasing attention from entomologists. In this study, we identified the gene that encodes the olfactory receptor co-receptor (OrCo). Through amino acid sequence alignment, we found that LdisOrCo shares high identity with other OrCo proteins from different insect orders. Next, we performed RNA-interference (RNAi) to assess the role of OrCo in olfaction. Electroantennographic assays showed that after RNAi, the average value of males' response to sex pheromones was $0.636 \mathrm{mV}$, significantly lower than that of the positive control (average $=1.472 \mathrm{mV}$ ). Females showed no response to sex pheromones before or after RNAi. Finally, quantitative PCR showed a strong decrease in the expression of $\operatorname{OrCo}$ after RNAi, by $\sim 74 \%$ in males and by $23 \%$ in females relative to the positive controls. These results indicate that OrCo is not only critical to odor recognition, but it may also represent a new target for development of semiochemicals that can influence insect behavior.
\end{abstract}

Key words: Lymantria dispar, RNA interference, OrCo, EAG, qPCR

\section{Introduction}

Insects are among the most abundant and diverse multicellular animals, with approximately one million species identified to date, and they play an important role in the biosphere. Numerous insect pests can cause severe damage to agricultural crops, forests, and humans. This paper focuses on the gypsy moth, Lymantria dispar, an economically important insect that can severely disrupt forested ecosystems worldwide. The gypsy moth population cycle rises and falls, alternating between low numbers and large-scale outbreaks; during outbreaks, the moths cause extensive damage to plant foliage that can lead to massive tree death [1]. Most insect behaviors, such as mating, feeding, and nesting, are closely related to olfaction. Odorant-binding proteins and olfactory receptors (Ors) are primarily involved in semiochemical transduction [2-7]. Olfactory receptor complexes of unknown stoichiometry consist of a conserved ion channel named olfactory receptor co-receptor (Orco) [8-11] and a diverse ligand-binding olfactory receptor molecule (Ors) [2, 8, 12]. OrCo proteins have been found in Lepidoptera, Coleoptera, Hymenoptera, and 
Diptera [13, 14]. OrCo amino acid sequences are highly conserved among insects, in contrast to traditional olfactory receptors, suggesting that these proteins have specific, key functions in different insect species. Knockout of Ors has revealed that OrCo proteins are required for insect olfaction [15-17].

While there is agreement that Orco locates and maintains Ors on the dendritic membranes of olfactory receptor neurons, there is no consensus on the physiological function of Orco in the olfactory signal transduction cascade. There are three theories about Orco function. The first is that Ors and Orco form a ligand-gated olfactory receptor ion channel complex that underlies ionotropic odor transduction only in insects [18]. The second theory suggests a mixed ionotropic and metabotropic odor transduction cascade with Ors coupling to G-proteins [19]. The final theory suggests that Orco is not involved in ionotropic odor transduction but rather forms an ion channel that controls spontaneous activity, sensitivity, and the time course of odor transduction [17].

Here, we first identified the $\mathrm{OrCo}$ gene in the gypsy moth, and we analyzed evolutionary relationships between $\mathrm{OrCo}$ genes in different species. Next, we knocked down OrCo genes with RNAi. The response of mutant moths to sex pheromones, measured with the EAG method, was compared to that of wild-type moths. OrCo expression was then verified with qPCR, and its role in the olfactory mechanism in gypsy moths was further clarified.

\section{Materials and methods}

\section{Insect samples}

Male and female gypsy moths were obtained from the Research Institute of Forest Ecology, Environment and Protection, Chinese Academy of Forestry, Beijing, China. Antennae were stored in RNAlater ${ }^{\circledR}$ RNA Stabilization Solution (Invitrogen) at $-80^{\circ} \mathrm{C}$.

\section{RNA extraction and cDNA synthesis}

Frozen antennae from males and females were ground under liquid nitrogen. Then, following the protocols for an RNA simple Total RNA Kit (Invitrogen, Germany), total RNA was eluted in $40 \mu \mathrm{L}$ RNase-free water and stored at $-80^{\circ} \mathrm{C}$.

The first strand of complementary DNA (cDNA) was synthesized using a Quantscript RT Kit. Total RNA solution, the template, was transcribed into cDNA in a $20-\mu \mathrm{L}$ reaction volume containing $2 \mu \mathrm{L}(10$ $\mu \mathrm{M})$ oligo-d $\mathrm{dT}_{15}$ primer, $2 \mu \mathrm{L} 10 \times \mathrm{RT}$ Mix, $2 \mu \mathrm{L}(2.5 \mathrm{mM}$ each) Super Pure dNTP, $1 \mu \mathrm{L}$ Quant reverse transcriptase, and $3 \mu \mathrm{L}$ RNase-free $\mathrm{dd}_{2} \mathrm{O}$. This synthesis was performed for $60 \mathrm{~min}$ at $37^{\circ} \mathrm{C}$ followed by stor- age at $-20^{\circ} \mathrm{C}$.

\section{Cloning of OrCo sequences from Lymantria dispar}

cDNA were prepared as described above. Because of the conservation of $\mathrm{OrCo}$ in other Lepidopterans, degenerate primer pairs were designed according to the conserved sequence as follows:

OR1F, 5'-YTHATYGARGAGAGYTCATC-3',

OR1R, 5'-GYTGBAYCAAYACCATGAAG-3',

OR2F, 5'-GVWCHGCBATMAARTAYTGGG-3',

OR2R, 5'-TCCATHACBGATGARCTCTC-3',

OR3F, 5'-GAVGTCAAYGADCTVACVGC-3',

OR3R, 5'-ACGACATGCTTATGCCTCTC-3',

PCR amplification was performed with the following conditions: a denaturing step at $95{ }^{\circ} \mathrm{C}$ for 5 min, followed by 35 cycles $\left(95^{\circ} \mathrm{C}\right.$ for $30 \mathrm{~s}, 55^{\circ} \mathrm{C}$ for 30 $\mathrm{s}, 72{ }^{\circ} \mathrm{C}$ for $30 \mathrm{~s}$ ), and a final step of $7 \mathrm{~min}$ at $72{ }^{\circ} \mathrm{C}$. The 200-bp PCR product was purified and ligated into a pUC 19-T vector (Takara, China). After transformation, the competent cells were plated on LB/agar containing ampicillin, isopropyl thio- $\beta$-D-galactoside (IPTG), and 5-bromo-4-chloro-3-indolyl- $\beta$-Dgalactoside $(\mathrm{X}-\mathrm{Gal})$. White colonies were then grown in liquid LB/ampicillin and analyzed for the presence of the positive clone. More than 10 independent clones were sequenced.

Based on the sequence of the fragment obtained by reverse transcription-polymerase chain reaction (RT-PCR), gene-specific primers were synthesized and used for rapid amplification of cDNA ends (RACE). RACE was performed using the RLM-RACE kit (Ambion) according to the manufacturer's protocol. A first 35-cycle nested PCR was performed using the 5' RACE outer primer 5'-CATGGCTACATG CTGACAGCCTA-3' in combination with the specific primer 5'1, CCCAGTGTATAACCGAGATAGCCG. The second 35-cycle nested PCR was performed using the sequence 5'-CGCGGATCCACAGCCTACTG ATGATCAGTCGATG-3' as the 5' RACE inner primer in combination with sequence $5^{\prime} 2$, CAGAGTAG TACCGTATGTGTCTCC. For 3' RACE, a first 35-cycle nested PCR was performed using the $3^{\prime}$ RACE outer primer $5^{\prime}$-TACCGTCGTTCCACTAGTGATTT- $3^{\prime}$ in combination with the specific primer 3'1, GGAGACACATACGGTACTACTCTG. The second 35-cycle nested PCR was performed using the sequence 5'-CGCGGATCCTCCACTAGTGATTTCAC TATAGG-3' as the $3^{\prime}$ RACE inner primer in combination with sequence $3^{\prime} 2$, CGGCTATCTCGG TTATACACTGGG. Each of the 35 cycles consisted of $30 \mathrm{~s}$ at $94{ }^{\circ} \mathrm{C}, 30 \mathrm{~s}$ at $55^{\circ} \mathrm{C}$, and $1 \mathrm{~min}$ at $72{ }^{\circ} \mathrm{C}$. The amplified product was purified, cloned, and sequenced on both strands. 


\section{Sequence analysis}

We conducted homology analysis on the NCBI website, sequence analysis on DNAMAN and multiple aligned sequences homology analysis on CLC Sequence Viewer 6. The TMHMM program (http://www.cbs.dtu.dk/services/TMHMM) was used to analyze transmembrane domains of OrCo. The phylogenetic tree of insect odorant receptors was built using Mega5.1 using the neighbor-joining method with Bootstrap [20].

\section{RNAi of OrCo genes}

The cDNA products were prepared, the double-stranded RNA (dsRNA) of OrCo genes was generated using the cDNA template and MEGAscript RNAi kit, and the new primers were designed using Primer Premier 5.0 (Table 1). The concentration of dsRNA (three measurements) was $615 \mathrm{ng} / \mu \mathrm{L}$ for females and $650 \mathrm{ng} / \mu \mathrm{L}$ for males. Approximately $0.5 \mu \mathrm{L}$ (400 ng) of dsRNA was injected through the thorax membranes into the pupae with a microinjector.

Four treatments were tested using the injection volumes shown in Table 2 and an injection depth of 2-3 mm. Each kind of dsRNA was injected into 15 moths. All pupae were injected once every 2 days until emergence. The antennae of 2- or 3-day-old adults were removed; one antenna was used to analyze the response to the pheromone using EAG, and the other was collected for relative qRT-PCR.

Table 1. Primers for generating dsRNA of OrCo genes.

\begin{tabular}{ll}
\hline Primer & Sequence $\left(5^{\prime}-3^{\prime}\right)$ \\
\hline Or- & TAATACGACTCACTATAGGGAGAATAACCCTAATGGAC \\
Co-Forward & TTTCA \\
Or- & TAATACGACTCACTATAGGGAGAAAATAAGTTACCACA \\
Co-Reverse & GCACC \\
\hline
\end{tabular}

Table 2. Injection volume of dsRNA in each treatment.

\begin{tabular}{llllll}
\hline Treatment & Sex & $\begin{array}{l}\text { Number of } \\
\text { pupae }\end{array}$ & $\begin{array}{l}\text { OrCo } \\
(\mu \mathrm{L})\end{array}$ & $\begin{array}{l}\mathrm{ddH}_{2} \mathrm{O} \\
(\mu \mathrm{L})\end{array}$ & $\begin{array}{l}\text { Total vol- } \\
\text { ume }(\mu \mathrm{L})\end{array}$ \\
\hline $\mathrm{ddH}_{2} \mathrm{O}$ (Control) $)$ & Female & 15 & 0 & 1.75 & 1.75 \\
& Male & 15 & 0 & 1.70 & 1.70 \\
\multirow{2}{*}{ OrCo } & Female & 15 & 0.65 & 1.10 & 1.75 \\
& Male & 15 & 0.62 & 1.08 & 1.70 \\
\hline
\end{tabular}

\section{EAG Assay}

The high-efficiency sex pheromone used in the EAG assay was produced by Trece Inc. (Adair, OK). We then used $n$-hexane to dissolve and dilute the compound in a concentration gradient of 0.00005 , $0.0005,0.005,0.05$, and $0.5 \mathrm{mg}$. Considering the differential sensitivity of antennae, the response value to $1 \mathrm{mg}$ of sex pheromone was regarded as a reference control (i.e., 100\%); all other values were obtained relative to the reference.

Both ends of adult antennae were cut and blocked with a drop of conductive adhesive, and the basal part was linked to a reference electrode while the distal end was connected to the recording electrode. Both electrodes were connected to an amplifier (Syntech, Hilversum, the Netherlands). Charcoal-filtered, humidified air was delivered at a constant flow rate of $150 \mathrm{~mL} / \mathrm{min}$; the stimulus flow was $2.5 \mathrm{~mL} / \mathrm{s}$, and the time of stimuli was $0.5 \mathrm{~s}$ with a $40-\mathrm{s}$ interval. Chemical solutions $(10 \mu \mathrm{L})$ were added to 1 $\mathrm{cm} \times 2 \mathrm{~cm}$ filter paper; the folded papers were put into glass tubes as a stimuli source, and the same volume of n-hexane was added as a solvent control. To verify the more sensitive concentrations, the wild moths were measured with different concentrations of pheromone. The treated antennae were then analyzed with the more sensitive concentration of pheromone, and the antennae were stimulated alternately, three times, with pheromone and solvent. A minimum of three male or female antennae were measured for each treatment, and the reaction values were recorded. The antennae were stimulated three times with 0.5 mg sex pheromone dissolved in $n$-hexane (ck) before and after pheromone stimulation.

\section{Real-time relative quantitative PCR}

We collected another set of gypsy moth antenna that had been treated with dsRNA. RNA extraction and synthesis of first-strand cDNA were performed according to methods described above. The primers used for the $\mathrm{OrCo}$ gene and the reference actin gene are shown in Table 3. A Roche LightCycler 480II was used for qPCR.

Table 3. Primers for $q P C R$ of OrCo and actin genes.

\begin{tabular}{ll}
\hline Primer & Sequence $\left(5^{\prime}-3^{\prime}\right)$ \\
\hline Actin-Forward & GGGAAATCGTGCGTGAC \\
Actin -Reverse & GAAGGAAGGCTGGAAGAG \\
OrCo-Forward & GCAGAGTTATTCCGAGCAT \\
OrCo-Reverse & GTCCATTAGGGTTATTTCCA \\
\hline
\end{tabular}

The optimized qPCR conditions (annealing temperature, primer density, and reaction time) consisted of a denaturing step at $94^{\circ} \mathrm{C}$ for $5 \mathrm{~min}$; followed by 40 cycles of $94{ }^{\circ} \mathrm{C}$ for $40 \mathrm{~s}, 55^{\circ} \mathrm{C}$ for $30 \mathrm{~s}, 72^{\circ} \mathrm{C}$ for $30 \mathrm{~s}$; a melting curve program including $95^{\circ} \mathrm{C}$ for 1 min, $65^{\circ} \mathrm{C}$ for $1 \mathrm{~min}, 95^{\circ} \mathrm{C}$ for continuous; and a final step of $10 \mathrm{~s}$ at $40{ }^{\circ} \mathrm{C}$. Fluorescence signals were measured during the annealing steps of each cycle.

The reaction system was prepared in a 96-well plate; the components are shown in Table 4. Each treatment included three replicates on one 96-well plate, and each treatment was repeated three times. 
Table 4. Components of qPCR reaction system.

\begin{tabular}{lll}
\hline Reagent & Quantity & Final concentration \\
\hline SYBR® Premix Ex TaqTM $(2 \times)$ & $12.5 \mu \mathrm{L}$ & $1 \times$ \\
PCR Forward Primer $(10 \mu \mathrm{M})$ & $1 \mu \mathrm{L}$ & $0.4 \mu \mathrm{M}$ \\
PCR Reverse Primer $(10 \mu \mathrm{M})$ & $1 \mu \mathrm{L}$ & $0.4 \mu \mathrm{M}$ \\
Template (cDNA) & $1 \mu \mathrm{L}$ & \\
dH2O & & $9.5 \mu \mathrm{L}$ \\
Total & & $25 \mu \mathrm{L}$ \\
\hline
\end{tabular}

The relative qPCR were analyzed using the Advanced Relative Quantification method. The cycle threshold (CT) was calculated, and the $2^{-\Delta \Delta C T}$ method was used to show the differential expression.

\section{Results}

\section{Identification of olfactory receptors (Ors)}

cDNA was obtained by reverse transcription and was used as a template for the PCR, and degenerate primers were designed. We obtained a 200-bp fragment that was connected with the pGEM-T easy vector. The vector was transformed into E. coli DH5a, and 10 colonies were sequenced. According to the BLAST homology search, the target sequence belongs to
Lepidoptera olfactory receptor genes. The primers for 3' RACE and 5' RACE were designed based on the fragment sequence. The entire OrCo sequence was $1532 \mathrm{bp}$ in length and was named LdisOrCo (GenBank accession number KF482409). The open reading frame was 1311 bp (436 amino acids; Fig. 1). The transmembrane structure indicated that the amino acids have seven putative transmembrane regions with a helices, similar to a typical G-protein coupled receptor (Fig. 2).

Previous studies have shown that the OrCo receptor is highly conserved in insect evolution, and therefore known Lepidopteran relatives were selected for alignment, including bollworm (Helicoverpa armigera Or83b), tobacco budworm (Helicoverpa assulta Or83b), and cutworm (Spodoptera litura Or83b). Sequences of representative insects from Coleoptera, Diptera, and Hymenoptera were also chosen for the alignment. Our results showed that the LdisOrCo gene was $89 \%$ homologous with the related species (Spodoptera littoralis Or83b), 64\% homologous with Taiwanese black beetles (Holotrichia plumbea Or83b), and $>60 \%$ homologous with other insects (Fig. 3). The C-terminal was highly conserved.

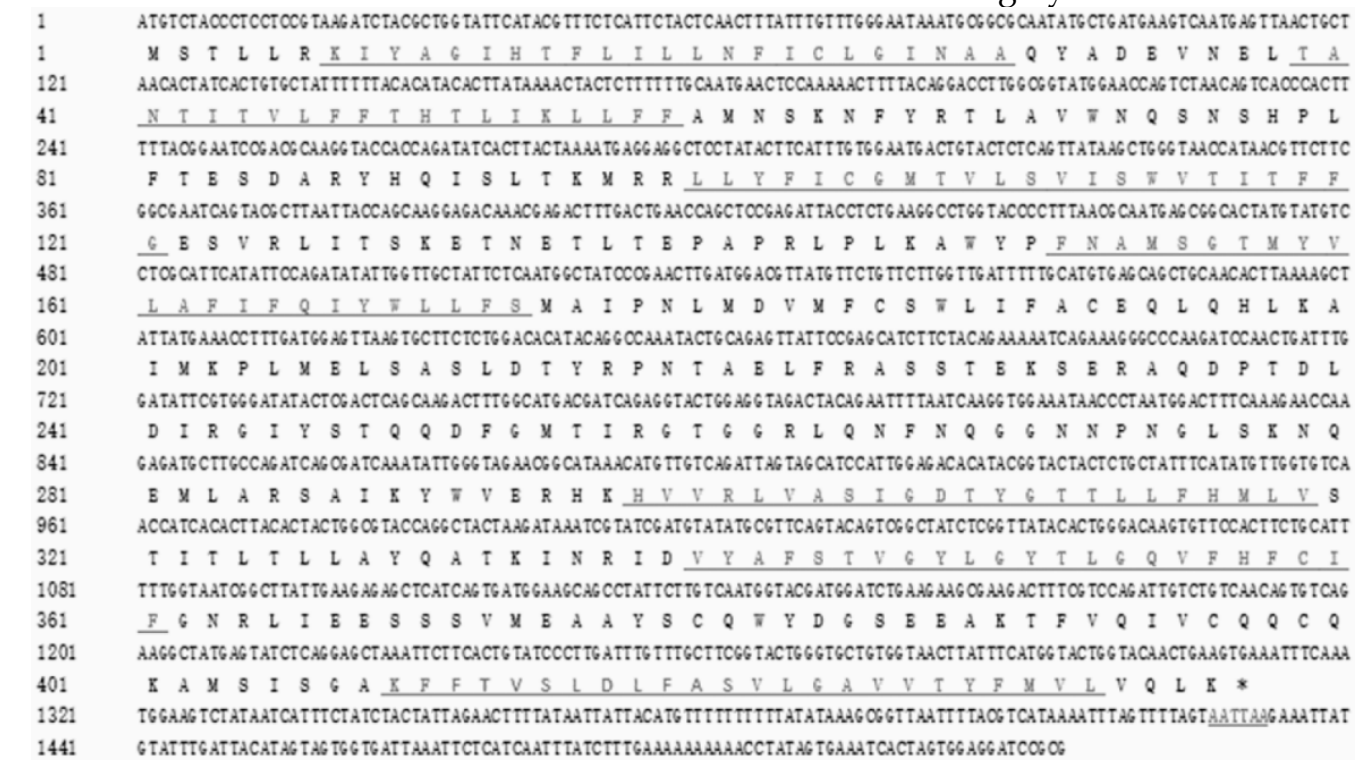

Figure 1. Nucleotide and amino acid sequences of the OrCo gene in Lymantria dispar.

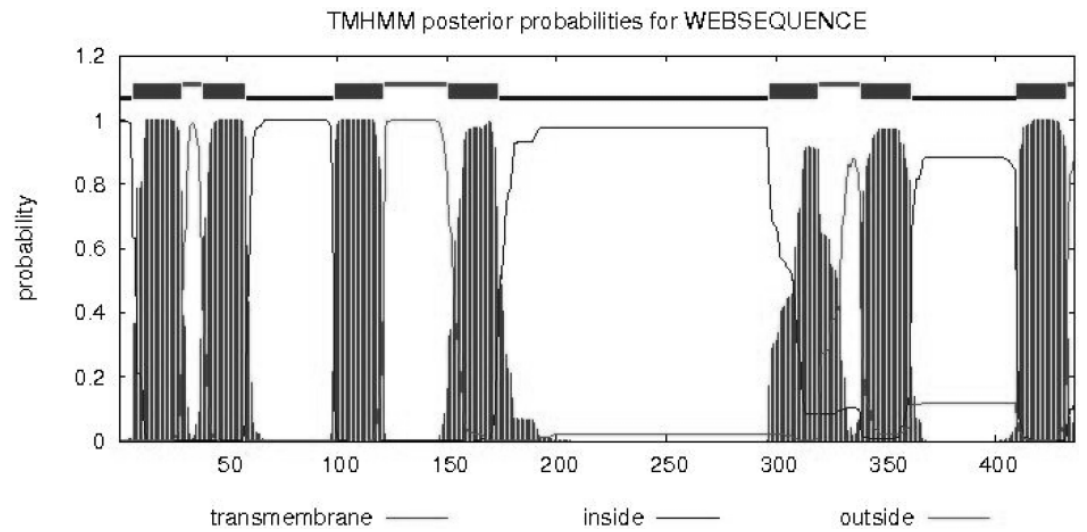

Figure 2. Analysis of transmembrane region of the OrCo gene in Lymantria dispar. 


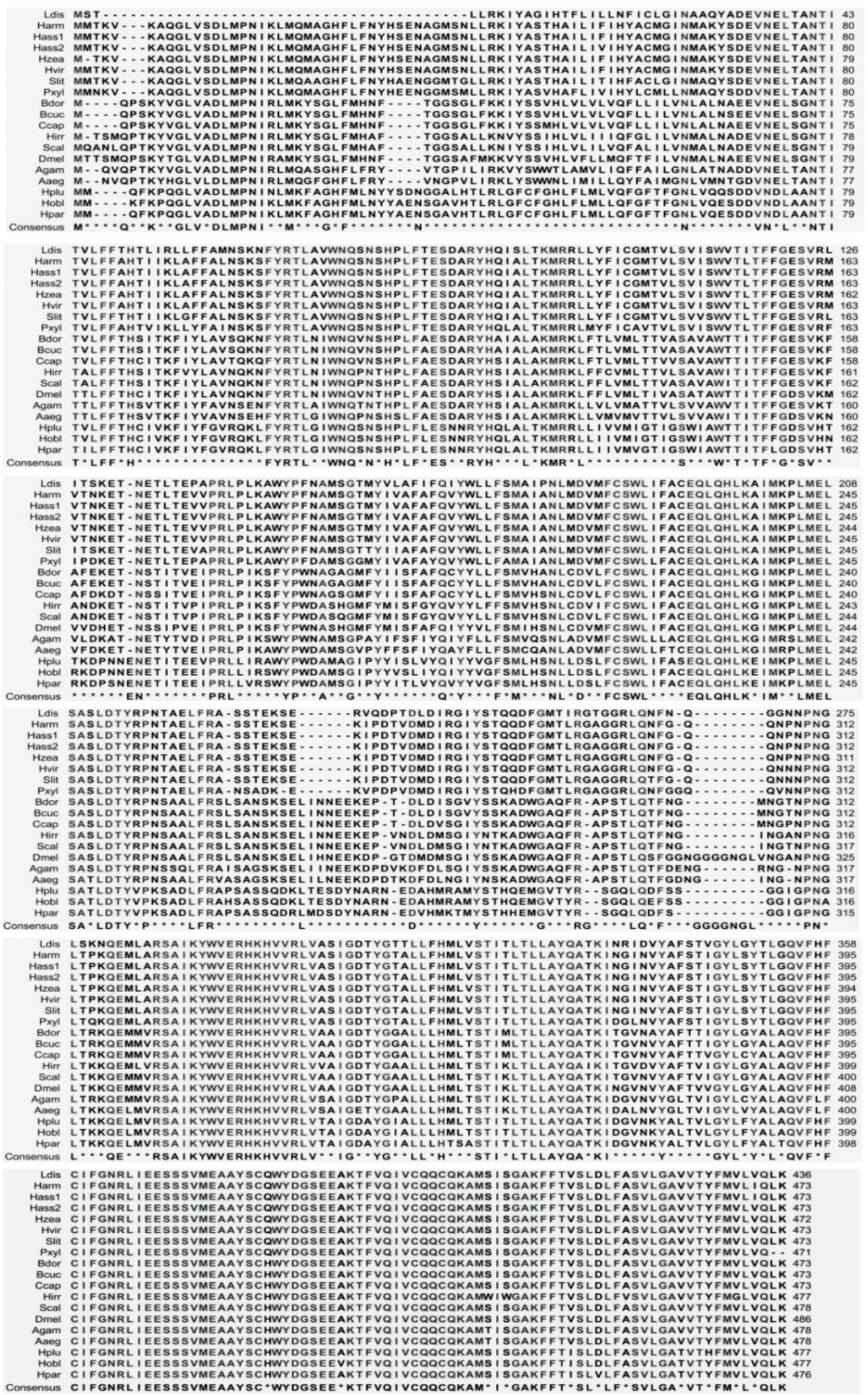

Figure 3. Alignment of amino acid sequences of $L$ disOrCo to selected OrCo proteins of various insect species. Amino acids that were identical in all sequences are shown in consensus lines. GenBank accession numbers for olfactory receptors are as follows: Lymantria dispar (Ldis,OrCo,mRNA,KF482409); Helicoverpa armigera (Harm,Or83b,mRNA,HQ186284); Helicoverpa assulta (Hass 1,Or83b,mRNA,HQ186285); Helicoverpa assulta (Hass2,Or83b,mRNA,EU057178); Helicoverpa zea (Hzea,Or83b,mR-NA,AY843204); Heliothis viriplaca (Hvir,Or83b,mRNA,JQ394904); Spodoptera litura (Slit,Or83b,mRNA,JQ811935); Plutella xylostella (Pxyl,Or83b,mRNA,GQ923610); Bactrocera dorsalis (Bdor,Or83b,mRNA,EU621792); Bactrocera cucurbitae (Bcuc,Or83b,mRNA, HM745934); Ceratitis capitata (Ccap,Or83b,mRNA,AY843206); Haematobia irritans (Hirr,Or83b, mRNA,EU622915); Stomoxys calcitrans (Scal,Or83b,mRNA,EU622914); Drosophila melanogaster (Dmel,Or83b,mRNA,AY567998); Anopheles gambiae (Agam,Or83b,mRNA,AY843205); Aedes aegypti (Aaeg,Or83b,mRNA,XM_001651376); Holotrichia plumbea (Hplu,Or83b,mRNA,HQ1 10087); Holotrichia oblita (Hobl,Or83b,mRNA,JF718662); Holotrichia parallela (Hpar,Or83b,mRNA,JF826514). 


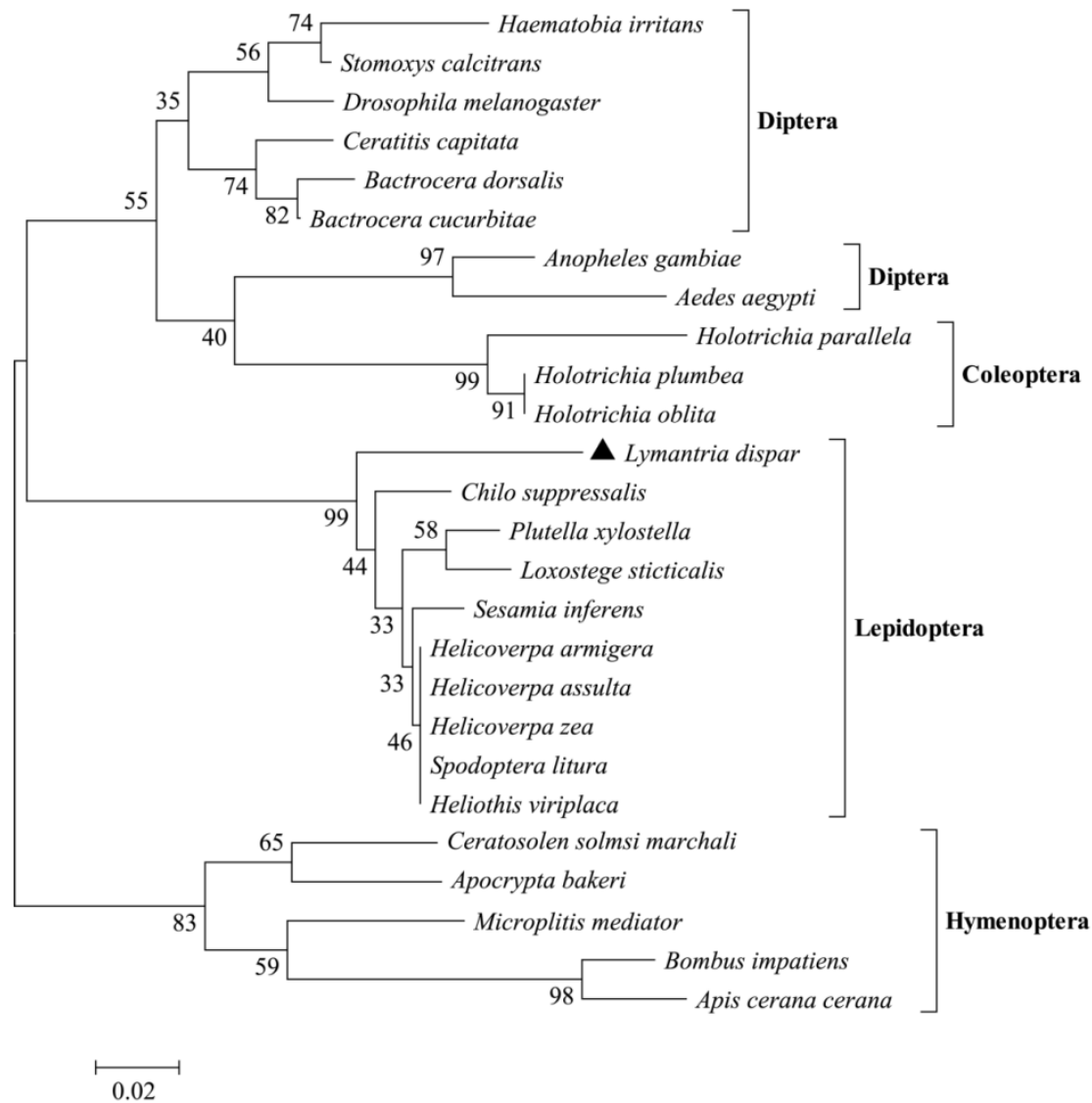

Figure 4. Neighbor-joining phylogenetic tree of the OrCo gene encoding olfactory receptors in various insects.

Using Mega 5.1, we performed phylogenetic analysis of odorant receptors in insects from the orders Diptera, Coleoptera, Hymenoptera, and Lepidoptera. After 1500 iterations, the evolutionary relationships between these insect orders became apparent (Fig. 4). The evolutionary tree showed that the 26 odorant receptor genes formed three major branches, with Coleoptera and Diptera belonging to one large branch, and Lepidoptera and Hymenoptera each occupying one branch. The closer evolutionary relationship between Coleoptera and Diptera was reflected in conservative characteristics for the genes of these orders. LdisOrCo had a close genetic relationship with Orco of other Lepidopteran insects.

\section{RNAi and electrophysiological assay}

The dsRNA of each gene was detected by agarose gel electrophoresis and was approximately 600 bp (Fig. 5A), which was suitable for performing qPCR. After measuring the concentrations, $400 \mathrm{ng}$ dsRNA was injected as illustrated in Figure 5B. The optimal concentration of pheromone to excite wild-type moths was screened (Fig. 6) and defined as $0.5 \mathrm{mg}$ of sex pheromone.
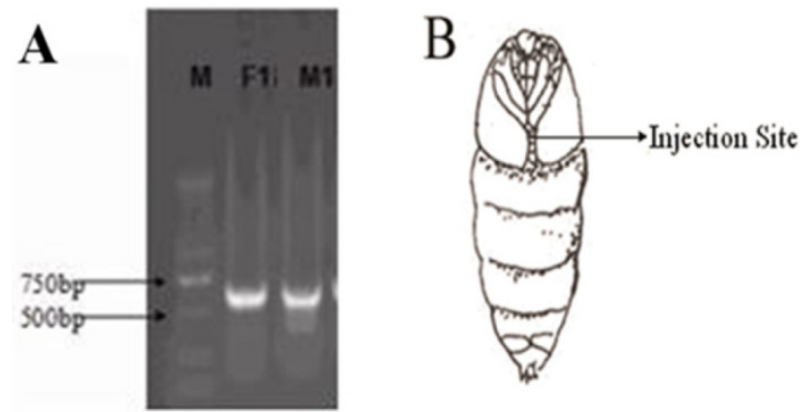

Figure 5. A: Electrophoretic diagram of purified dsRNA of the OrCo gene in male and female gypsy moths. M, DNA marker; F1, female OrCo; MI, male OrCo. B: dsRNA injection site.

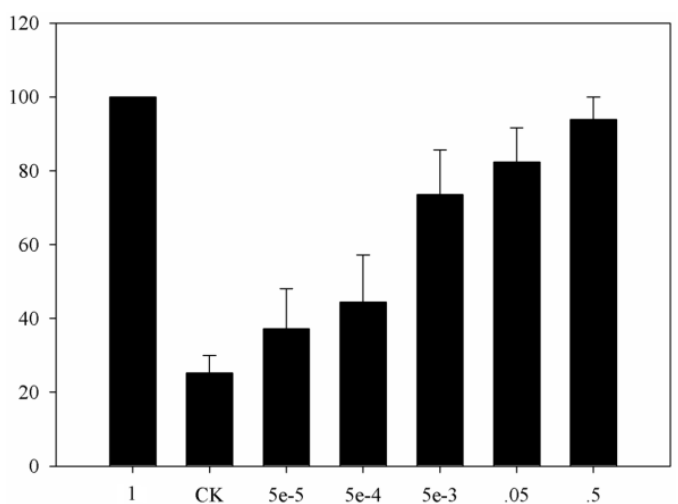

Figure 6. Electrophysiological recording of adult male response to different amounts of pheromone. CK indicates solvent. One milligram of sex pheromone was regarded as the reference with which the other values were compared. 
Adults (2- or 3-day-old) were analyzed by electrophysiological assay; the reaction values are illustrated in Fig.7. The average response values of positive controls injected with water were $0.101 \mathrm{mV} \pm 0.003$ to $n$-hexane and $1.472 \mathrm{mV} \pm 0.046$ to sex pheromone, and RNAi moths injected with dsRNA were 0.212 $\mathrm{mV} \pm 0.007$ to $n$-hexane, $0.636 \mathrm{mV} \pm 0.01$ to sex pheromone, decreasing $57 \%$ compared with the response of positive control moth to sex pheromone. The $t$-tests showed that the response to sex pheromone was significantly reduced $(P<0.05)$ after injection with Orco dsRNA, and the response to $n$-hexane was not significantly different between the positive control and RNAi moths. Because the female control did not respond to the sex pheromone, the reaction values were recorded for male antennae only.

\section{Real-time qPCR}

We conducted general PCR amplification using the primers shown in Table 3 . The target $\mathrm{OrCo}$ fragments and actin genes were $\sim 200 \mathrm{bp}$ after sequencing. The qPCR data were further processed using the $2^{-\triangle \triangle C T}$ method to analyze differences in expression between target and reference genes (Table 5).

Although antennae from females did not respond to sex pheromones, Orco expression was reduced and the value of $2^{-\Delta \Delta \mathrm{CT}}$ was $0.77,23 \%$ less than that of the control. Orco expression in males was significantly decreased, and the value of $2^{-\Delta \Delta \mathrm{CT}}$ was 0.26 , $74 \%$ lower than the control. The magnitude of the decline was slightly higher than that of the EAG value.

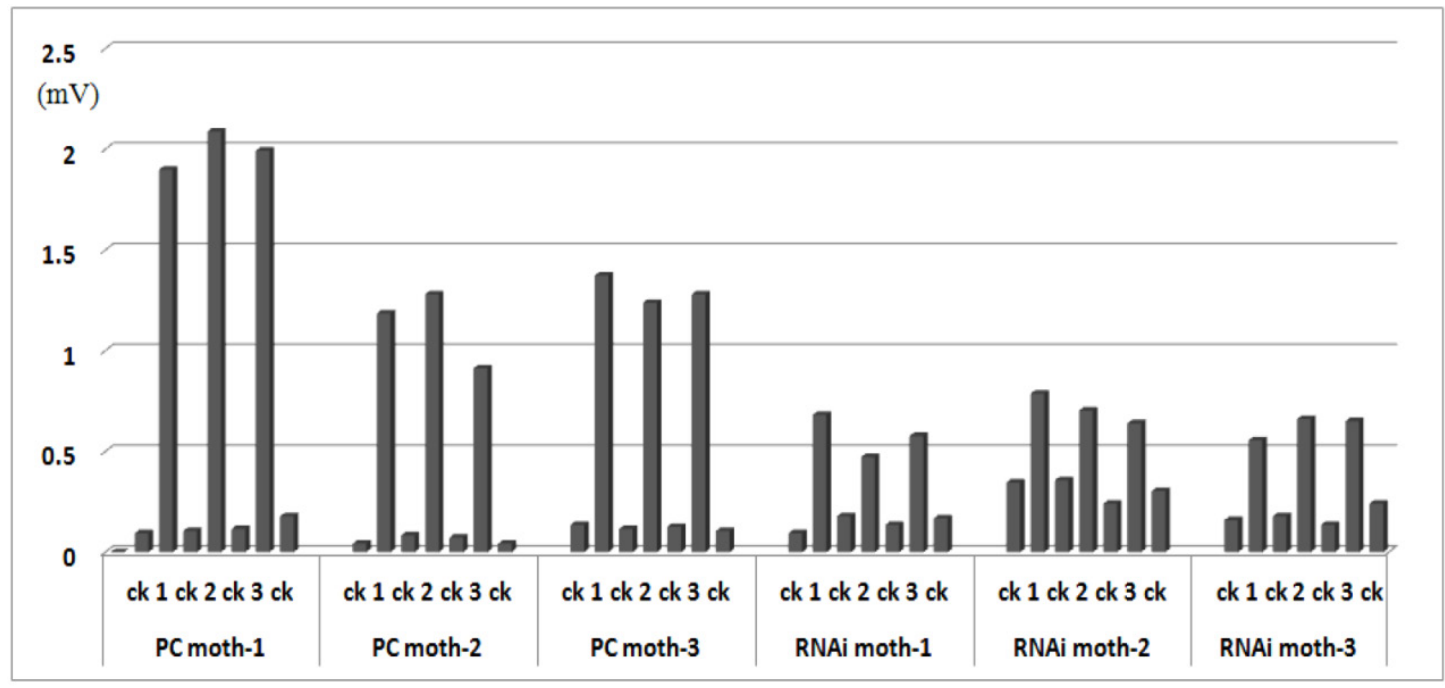

Figure 7. Electrophysiological response in adult males. PC indicates positive control moths injected with water; RNAi indicates treated moths injected with Orco dsRNA. Each treatment included three moths. Antennae were stimulated three times (labeled 1, 2, and 3) with $0.5 \mathrm{mg}$ sex pheromone dissolved in $n$-hexane (ck), and ck was used to stimulate the antennae before and after pheromone stimulation.

Table 5. Differential gene expression in adult female and male Lymantria dispar.

\begin{tabular}{|c|c|c|c|c|c|c|c|}
\hline dsRNA combination & Target & Reference & Mean CT of target & Mean CT of reference & $\Delta \mathrm{CT}$ & $\Delta \Delta \mathrm{CT}$ & $2-\Delta \Delta C T$ \\
\hline F-Orco & Orco & actin & 32.074 & 31.284 & 0.790 & 0.711 & $0.77 \pm 0.23$ \\
\hline F-CK & Orco & actin & 33.520 & 33.440 & 0.079 & 0 & 1 \\
\hline M-Orco & Orco & actin & 30.440 & 27.724 & 2.716 & 2.316 & $0.26 \pm 0.09$ \\
\hline M-CK & Orco & actin & 33.567 & 33.167 & 0.340 & 0 & 1 \\
\hline
\end{tabular}

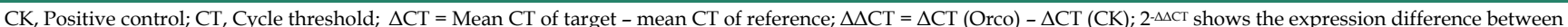
Orco and CK $( \pm \mathrm{SE})$.

\section{Discussion}

In this study, we identified genes encoding OrCo proteins in Lymantria dispar. This is the first olfactory receptor gene identified in this economic pest to date. Sequence alignment and homology analysis demonstrated significant conservation of OrCo among different insects, even among different orders. As shown in Figure 3, the C-terminal domains were especially highly conserved among all aligned sequences, which indicated their relevance to the function of $\mathrm{OrCo}$. OrCo is broadly expressed in most olfactory sensory neurons as the critical, constant subunit of the heteromultimeric insect Or that forms a receptor complex $[13,15,21-24]$. In addition, the transmembrane topology of OrCo differs from that of conventional Ors, with the intracellular location of the N-terminus and the extracellular location of the C-terminus $[19,25]$. 
The C-terminus was presumed to strongly influence this Or-OrCo complex, and the complex was regarded as a ligand-gated ion channel $[18,19,26]$.

EAG showed that female L. dispar did not respond to the sex pheromone. We suggest a two-part explanation for this finding. First, Or-based recognition of the sex pheromone are not expressed in females, and OrCo and Or cannot form the complex that is required for this function. Second, olfactory receptor neurons in female moths may only be capable of responding to general odors. qPCR showed that OrCo expression declined to different degrees in male and female moths, which could suggest that knockdown of the OrCo gene influences the response to pheromone. Similar results were reported for RNAi of Orco in Tribolium castaneum and Phyllotreta striolata [27, 28]. Results showed that gypsy moths showed severe olfactory defects when the expression of $\mathrm{OrCo}$ was reduced, which demonstrated the crucial role of this gene in this species' olfactory sensory mechanism. EAG showed $57 \%$ decrease and qPCR $74 \%$ decrease, and the difference of decrement indicated that not all the Ors form the Orco-Or complex to recognize the chemical signals. However, this experiments made cannot distinguish between the different hypotheses suggested for the physiological function of Orco. The function is also related to temporal and spatial gene expression; Orco is expressed in antennae and in maxillary palps of larval, pupal, and adult Anopheles gambiae, and in all developmental stages of male Culex pipiens pallens [14, 29]. In Lepidoptera, OrCo is specifically expressed in antenna throughout the life cycle, except for the embryonic period [30]. The developmental characteristics of OrCo function in gypsy moths require further clarification.

Olfactory signaling is a target for pest management, with attempts to interfere with and thus disrupt odorant- or pheromone-driven behaviors. Many investigations of pheromones have been performed in recent decades; it has been assumed that no single, general design can be applied in developing pheromones that are analogous for all species [31]. However, OrCo could be a key to controlling various insect pests. Agonistic and antagonistic effects have been investigated in insects based on the conserved Orco, such as the stimulant VUAA1 [32,33], which provides a foundation for pest control. The sequence and function of OrCo identified here in gypsy moths can inform further research on olfactory-based pest-management strategies and can be applied to improve and protect forest health.

\section{Abbreviations}

cDNA: complementary DNA; CT: cycle threshold; dsRNA: double-stranded RNA; EAG: electroan- tennography; IPTG: isopropyl thio- $\beta$-D-galactoside; OrCo: olfactory receptor co-receptor; Ors: olfactory receptors; qPCR: quantitative PCR; RACE: rapid amplification of cDNA ends; RNAi: RNA-interference; RT-PCR: reverse transcription-polymerase chain reaction; X-gal: 5 -bromo-4-chloro-3-indolyl- $\beta$-Dgalactoside.

\section{Acknowledgement}

This work was supported by the Fundamental Research Funds of the Chinese Academy of Inspection and Quarantine (Grant No. 2013JK004, 2014JK018 ), the Beijing Nova Program (Z131105000413048) and the National Science and technology support program (2015BAD08B01).

\section{Author contributions}

WL and YY designed and performed the experiments. JZ, PZ and LD performed the RNAi experiment and analyzed the qPCR and EAG data. HC and SZ wrote the manuscript.

\section{Competing Interests}

The authors have declared that there are no competing interests.

\section{References}

1. Whittle A, Lenhart S and White KA. Optimal control of gypsy moth populations. Bull Math Biol. 2008; 70(2):398-411.

2. Grosse-Wilde E, Gohl T, Bouche E, Breer H and Krieger J. Candidate pheromone receptors provide the basis for the response of distinct antennal neurons to pheromonal compounds. Eur J Neurosci. 2007; 25(8):2364-73.

3. Horst R, Damberger F, Luginbuhl P, Guntert P, Peng G and Nikonova L, et al. NMR structure reveals intramolecular regulation mechanism for pheromone binding and release. Proc Natl Acad Sci USA. 2001; 98(25):14374-9.

4. Leal WS. Pheromone Reception. In: Schulz S, ed. Topics in Current Chemistry. Berlin: Springer Berlin Heidelberg. 2005: 1-36.

5. Leal WS, Ishida Y, Pelletier J, Xu W, Rayo J and Xu X, et al. Olfactory proteins mediating chemical communication in the navel orangeworm moth, Amyelois transitella. PLoS One. 2009; 4(9):e7235.

6. Miura N, Nakagawa T, Touhara K and Ishikawa Y. Broadly and narrowly tuned odorant receptors are involved in female sex pheromone reception in Ostrinia moths. Insect Biochem Molec. 2010; 40(1):64-73.

7. Nakagawa $T$, Sakurai $T$, Nishioka $T$ and Touhara $K$. Insect sex-pheromone signals mediated by specific combinations of olfactory receptors. Science. 2005; 307(5715):1638-42

8. Kurtovic A, Widmer A and Dickson BJ. A single class of olfactory neurons mediates behavioural responses to a Drosophila sex pheromone. Nature. 2007; 446(7135):542-6.

9. Olafson PU. Molecular characterization and immunolocalization of the olfactory co-receptor Orco from two blood-feeding muscid flies, the stable fly (Stomoxys calcitrans, L.) and the horn fly (Haematobia irritans, L.). Insect Mol Biol. 2013; 22(2):131-42.

10. Patch HM, Velarde RA, Walden K and Robertson HM. A Candidate Pheromone Receptor and Two Odorant Receptors of the Hawkmoth Manduca sexta. Chem Senses. 2009; 34(4):305-16.

11. Vosshall LB and Hansson BS. A Unified Nomenclature System for the Insect Olfactory Coreceptor. Chem Senses. 2011; 36(6):497-8.

12. Sakurai $T$, Nakagawa $T$, Mitsuno $H$, Mori $H$, Endo $Y$ and Tanoue $S$, et al. Identification and functional characterization of a sex pheromone receptor in the silkmoth Bombyx mori. Proc Natl Acad Sci USA. 2004; 101(47):16653-8.

13. Krieger J, Klink O, Mohl C, Raming $\mathrm{K}$ and Breer $\mathrm{H}$. A candidate olfactory receptor subtype highly conserved across different insect orders. J Comp Physiol A Neuroethol Sens Neural Behav Physiol. 2003; 189(7):519-26.

14. Pitts RJ, Fox AN and Zwiebel LJ. A highly conserved candidate chemoreceptor expressed in both olfactory and gustatory tissues in the malaria vector Anopheles gambiae. Proc Natl Acad Sci USA. 2004; 101(14):5058-63.

15. Larsson MC, Domingos AI, Jones WD, Chiappe ME, Amrein H and Vosshall LB. Or83b encodes a broadly expressed odorant receptor essential for Drosophila olfaction. Neuron. 2004; 43(5):703-14. 
16. Benton R. On the ORigin of smell: odorant receptors in insects. Cell Mol Life Sci. 2006; 63(14):1579-85.

17. Stengl M and Funk NW. The role of the coreceptor Orco in insect olfactory transduction. J Comp Physiol A. 2013; 199(11SI):897-909.

18. Sato K, Pellegrino M, Nakagawa T, Nakagawa T, Vosshall LB, Touhara K. Insect olfactory receptors are heteromeric ligand-gated ion channels. Nature 2008; 452(7190): 1002-1006.

19. Wicher D, Schäfer R, Bauernfeind R, Stensmyr MC, Heller R, Heinemann SH, Hansson BS. Drosophila odorant receptors are both ligand-gated and cyclic-nucleotide-activated cation channels. Nature 2008; 452(7190):1007-1011.

20. Kumar S, Nei M, Dudley J and Tamura K. MEGA: A biologist-centric software for evolutionary analysis of DNA and protein sequences. Briefings in Bioinformatics. 2008; 9(4):299-306.

21. Lundin C, Kall L, Kreher SA, Kapp K, Sonnhammer EL and Carlson JR, et al. Membrane topology of the Drosophila OR83b odorant receptor. Febs Lett. 2007; 581(29):5601-4.

22. Miller $\mathrm{R}$ and $\mathrm{Tu} \mathrm{Z}$. Odorant receptor c-terminal motifs in divergent insect species. J Insect Sci. 2008; 8: 53.

23. Krieger $M$ and Ross KG. Identification of a major gene regulating complex social behavior. Science. 2002; 295(5553):328-32.

24. Touhara $\mathrm{K}$ and Vosshall LB. Sensing odorants and pheromones with chemosensory receptors. Annu Rev Physiol. 2009; 71:307-32.

25. Wistrand M, Kall L and Sonnhammer EL. A general model of G protein-coupled receptor sequences and its application to detect remote homologs. Protein Sci. 2006; 15(3):509-21.

26. Nakagawa T, Pellegrino M, Sato K, Vosshall LB, Touhara K. Amino acid residues contributing to function of the heteromeric insect olfactory receptor complex. Plos ONE, 2012; 7(3):e32372.

27. Engsontia P, Sanderson AP, Cobb M, Walden KK, Robertson HM and Brown S. The red flour beetle's large nose: an expanded odorant receptor gene family in Tribolium castaneum. Insect Biochem Mol Biol. 2008; 38(4):387-97.

28. Zhao YY, Liu F, Yang G and You MS. PsOr1, a potential target for RNA interference-based pest management. Insect Mol Biol. 2011; 20(1):97-104.

29. Xia $Y$ and Zwiebel LJ. Identification and characterization of an odorant receptor from the West Nile virus mosquito, Culex quinquefasciatus. Insect Biochem Mol Biol. 2006; 36(3):169-76.

30. Dong X, Zhong G, Hu M, Yi X, Zhao H and Wang H. Molecular cloning and functional identification of an insect odorant receptor gene in Spodoptera litura (F.) for the botanical insecticide rhodojaponin III. J Insect Physiol. 2013; 59(1):26-32.

31. Renou M and Guerrero A. Insect parapheromones in olfaction research and semiochemical-based pest control strategies. Annu Rev Entomol. 2000; 45:605-30.

32. Jones PL, Pask GM, Rinker DC and Zwiebel LJ. Functional agonism of insect odorant receptor ion channels. Proc Natl Acad Sci USA. 2011; 108(21):8821-5.

33. Jones PL, Pask GM, Romaine IM, Taylor RW, Reid PR and Waterson AG, et al. Allosteric antagonism of insect odorant receptor ion channels. PLoS One. 2012; 7(1):e30304. 